\title{
EMBLEMAS PORTÁTILES: EL EMPLEO DE DIVISAS METÁLICAS COMO ADORNO DE SOMBREROS Y VESTIMENTAS, Y SU FUNCIÓN EN EL ORIGEN DEL GÉNERO EMBLEMÁTICO
}

\author{
PORTABLE EMBLEMS: THE USE OF METAL ISIGNIAS AS AN ADORN- \\ MENT ON HATS AND CLOTHING AND THEIR ROLE IN THE ORIGINS \\ OF THE EMBLEMATIC GENRE
}

\section{José Julio García Arranz}

Universidad de Extremadura

\begin{abstract}
The medieval custom of wearing figurative insignias on hats and caps became widespread during the 14th century when the uses and functions of these elements diversified and personal devises or badges became fashionable. As such, at the end of the Middle Ages and at the beginning of the 16th century, these portable "emblems" became commonly used objects, with their application on clothing becoming more and more frequent. In the present work, we will address the existing reciprocal relationship between printed emblem collections and appliqués for hats and clothing, in the sense that both creations date back decades to the definitive decline of metallic insignias.
\end{abstract}

KEYWORDS: Medieval insígnia, emblem, badge, devise, enseigne, emblem prototypes

RESUMEN: La costumbre medieval de portar insignias figuradas en sombreros y gorras se generaliza durante el s. XIV, momento en que los usos y funciones de estos elementos se diversifican, y se incorporan a la moda de las devises o badges personales. De este modo, a fines de la Edad Media e inicios del quinientos, estos «emblemas» portátiles devienen objeto de uso común, siendo cada vez más frecuente su aplicación a la indumentaria del momento. En el presente trabajo nos aproximaremos a la recíproca relación existente entre las colecciones de emblemas impresos y los apliques parlantes de sombreros y vestimentas, en el sentido de que ambas creaciones se retroalimentaron durante algunas décadas, hasta el declive definitivo de las insignias metálicas. ${ }^{1}$

PALABRAS CLAVES: Insignia medieval, badge, devise, enseigne, emblema, protoemblemática

1. El presente trabajo se inscribe en el proyecto de investigación Biblioteca digital Siglo de Oro IV (código FFI20123436), dirigido por la profesora Nieves Pena Sueiro y financiado por el Ministerio de Economía y Competitividad del Gobierno de España, en el marco del VI Plan Nacional de I+D+i 2008-2011. De igual modo, su realización y presentación han contado con ayudas procedentes del Gobierno de Extremadura y los Fondos Feder a través del Grupo de Investigación "PatrimoniofARTE. Unidad de Conservación del Patrimonio Artístico», dirigido por la Dra. Pilar Mogollón Cano-Cortés, en el que me integro. 
Uno de los pasajes esenciales a la hora de asomarnos a las distintas acepciones que el término "emblema" adoptó en nuestro Siglo de Oro es el que Sebastián de Covarrubias nos ofrece en su Tesoro de la lengua. En la entrada que reserva a este vocablo, texto, por lo demás, de sobra reiterado y conocido, a modo de introducción previa a la definición "metafórica» referida al celebrado artificio retórico implementado por Andrea Alciato, ${ }^{2}$ el autor hace un rápido recorrido por sus diversas raíces etimológicas. De este modo, tras aludir a los motivos de carácter figurado -en especial flores y animales entre otros temas- que se insertan en las grandes composiciones decorativas de mosaico -opus vermiculatum-, a los pavimentos y mesas de mármol o piedras ricas con labor de embutido, a determinadas creaciones de taracea o ataujía, o a los medallones circulares o elípticos de metal labrado que se incorporan como detalle ornamental en vasos de plata, aplique también frecuente «en fuentes, aguamaniles y salvillas», el canónigo conquense añade:

\section{Estos emblemas pusieron después en las go- rras y sombreros con figuras y motes, que comúnmente llamamos medallas, quasi metallas, nombre genérico, que coprehen- de la materia de oro, plata, cobre y los de- más metales de que se hazen para diversos usos de gala y ingenio, como los camafeos historiados y las demás pieças de escultura en relieve o cinzelado que sirven de bro- chas y botones o chapería (Covarrubias, 1611: $342 \mathrm{v}) .^{3}$}

Con tales indicaciones Covarrubias establece una suerte de identidad entre las insignias de sombreros y gorras y los em- blemas literarios, fundada no sólo en su común denominación: alude al empleo de las primeras para "diversos usos de gala y ingenio", es decir, a su doble vertiente de lucimiento ornamental y de artificio de agudeza conceptual, cualidades que comparte con las divisas o empresas coetáneas, en las que igualmente se dan cita lo decorativo y un "espíritu ingenioso y vivificador" que las anima, requisitos ambos que sentaron las bases para la configuración del emblema moderno. ${ }^{4}$

El de Covarrubias no es el único aserto que vincula los adornos figurados de la indumentaria y el género emblemático. El propio Andrea Alciato menciona hasta en dos ocasiones la posibilidad de que sus epigramas ilustrados pudieran servir de fuente de inspiración o modelo a los escultores y orfebres diseñadores de tales insignias. La primera vez, en una carta del jurista milanés al editor Francesco Calvo en 1522, en la que nos proporciona temprana noticia de su Emblematum liber -publicado por vez primera, como bien sabemos, nueve años más tarde-apuntando al respecto:

[...] he compuesto un librito de epigramas, al que di el título de Emblemata: puesto que describo en cada uno de los epigramas todo cuanto de distinguido se pueda extraer de la historia, o de los asuntos naturales, de donde pintores, orfebres, fundidores puedan [inspirarse para] realizar este tipo de cosas, que llamamos escudos -scuta- y que fijamos en los sombreros, o bien que portamos como insignias, tal como el ancla de Aldo, la paloma de Frobenio y el elefante de Calvo ya creadas desde hace tiempo, a las que nada iguala. ${ }^{5}$

2. «[...] versos que se subscriben a alguna pintura o talla, con que sinificamos algún concepto bélico, moral, amoroso o en otra manera, ayudando a declarar el intento del emblema y de su autor" (Covarrubias, 161 l: 342v; citamos por la edición de Madrid, Turner, 1984, voz «Emblema», p. 506. Cf. Horozco, 1604: I, 9v-10r).

3. Sobre la etimología antigua del término "emblema», puede consultarse Miedema, 1968: 239-240.

4. Como ha indicado José Antonio Maravall (1984: 204): «[...] la representación encubierta de conceptos bajo figuras, que, recurriendo preceptivamente a la agudeza del ingenio, practica el mundo de la caballería medieval, prepara el gusto por los emblemas».

5. El texto latino procede de Balavoine (1982: 53). La traducción es nuestra. 
Del mismo modo, en la dedicatoria de su colección de emblemas al consejero imperial de Augsburgo Konrad Peutinger, el autor insiste:

\begin{abstract}
Mientras los niños se entretienen con las nueces, y los jóvenes con los dados, y los juegos de cartas llenan el tiempo de los hombres ociosos; en los periodos festivos hemos acuñado estos Emblemata, con diseños realizados por artistas con mano ilustre: para que se fijen como ornamentos de los vestidos y como insignias de los sombreros, y para [uso de] cualquiera que sea capaz de escribir con lenguaje secreto (Alciato, 1531: A2r). ${ }^{6}$
\end{abstract}

Con ello se confirma la recíproca relación trazada entre las colecciones de emblemas impresos y los apliques parlantes de sombreros y vestimentas: si bien aquellas divisas para ornato de ropajes, cuyo uso se generaliza a partir de la segunda mitad del s. XIV, constituyen un claro precedente de la emblemática libresca, formando parte del complejo universo pre o para-emblemático que experimentó una singular efervescencia en el tránsito del s. XV al XVI, a su vez los emblemas ofrecen figuras y composiciones que retroalimentaron y perpetuaron durante algunas décadas más la moda de las insignias metálicas. En el presente trabajo, dadas las necesarias limitaciones de extensión, nos proponemos ofrecer una rápida aproximación a las tipologías, contenidos y funciones de las insignias portátiles que fueron portadas en gorras y otras prendas durante la Baja Edad Media y buena parte del quinientos.

\section{LAS INSIGNIAS METÁLICAS DE GORRAS Y SOMBREROS: BREVE HISTORIA DE SUS ORÍGENES, EVOLUCIÓN Y USOS DURANTE LA EDAD MEDIA}

Si bien los signa destinados al adorno de gorros y vestidos alcanzaron su apogeo a lo largo del s. XV y primeras décadas del XVI -de ello son testimonio tanto los ejemplos conservados, cuyos rasgos estilísticos permiten situarlos en estos momentos, como las abundantes muestras recogidas en la pintura coetánea, sobre las que más adelante volveremos-, su origen se remonta al s. XII. Se trata de piezas de pequeñas dimensiones, con apariencia de broche, que podían fijarse al tejido o cuero de los sombreros y capas. Con este fin solían estar provistas de unas arandelas metálicas soldadas a los bordes para su más fácil cosido a la prenda -a veces encontramos perforaciones en las mismas para idéntico propósito-, o, iniciado el s. XIV, de un largo alfiler y un cierre incorporados a la parte posterior que facilitaban aún más su ajuste. Los ejemplares medievales que han llegado a nosotros, procedentes esencialmente del drenaje de ríos $^{7}$ o fruto de hallazgos casuales, son por regla general manufacturas modestas, elaboradas con una aleación de plomo y estaño, aunque entre las clases más pudientes se lucieron broches de metales preciosos y apliques polícromos de esmalte, de los que hoy se conocen escasas muestras. ${ }^{8}$ Sea cual fuere su función, como veremos, no se tra-

6. La traducción es nuestra.

7. En efecto, estas insignias han sido recuperadas en su gran mayoría a raíz de la limpieza de ríos y arroyos, donde fueron voluntariamente arrojadas por cumplimiento de un voto, en agradecimiento de algún beneficio obtenido al santo figurado sobre el broche, o en espera de la obtención de alguna gracia; no faltan, por otra parte, los distintivos eliminados por su carácter políticamente comprometido. Unas 3.300 piezas de todo tipo fueron reunidas por el anticuario Arthur Forgeais, durante el segundo cuarto del s. XIX, al seguir de cerca los dragados que se efectuaron en esas fechas en el río Sena, colección que será adquirida posteriormente por el Museo de Cluny en París.

8. Sabemos por las fuentes que tales insignias podían estar, incluso, recortadas sobre tejido de cuero, pergamino o papel, o ser modeladas en terracota, tipos de apliques raramente conservados debido a su vulnerabilidad. 
taba en ningún caso de accesorios utilitarios de la vestimenta: constituían un signo, un objeto bien visible que proclamaba la identidad y posición de su portador, ya sea peregrino, fiel servidor de un príncipe, miembro de una facción política o testigo de un acontecimiento, y que, por tanto, actuaron como resorte de prestigio o privilegio. Tal y como sucede con los logos contemporáneos, la insignia medieval religiosa o profana, a través de las diferentes imágenes que porta, deviene marca identitaria de un colectivo, y proclama su integración en un acontecimiento o un grupo.

Es el historiador francés Denis Bruna (1996; 2006; 2007) quien nos ha ofrecido la más amplia y completa clasificación de insignias metálicas medievales a través de los ejemplares presentes en las principales colecciones europeas, atendiendo a su contenido o propósito. De este modo, todas ellas pueden agruparse en cinco grandes categorías:

a) Insignias de peregrino. Los más tempranos ejemplos conocidos, y cuantitativamente el conjunto más numeroso conservado de este tipo de emblemas portátiles, son los distintivos vinculados a la práctica del peregrinaje medieval. Conforme a una costumbre que se mantiene en la actualidad, y que se remonta a los tiempos antiguos, ${ }^{9}$ se trata de recuerdos que los devotos se llevan de la visita a un santuario o lugar de culto, y colocan sobre su sombrero a modo de recordatorio y prueba física del viaje: testimonium itineris in augmentum propriae devotionis. Producidos y vendidos por los artesanos a las puertas de las iglesias, su comercio se convertirá en actividad indisociable de la vida de los principales centros de devoción. ${ }^{10}$ Estas primeras piezas adoptaban, de manera necesariamente sintética, la forma del motivo que ellas honran -la figura de un santo, de su efigie milagrosa o de su principal relicario-, pudiendo por tanto responder a diseños diversos. Muy pronto se incorpora un breve texto, en una banda en el contorno de la insignia, o inserto en una filacteria, con una intención meramente identificativa: el nombre del santo o del santuario [fig. 1]; otras insignias recogen las primeras palabras de la salutación angélica, o bien escuetas sentencias destinadas a asegurar la protección del portador. Durante los ss. XIV y XV asistimos a una diversificación de los tipos de signa que ofrecen los centros de devoción, de modo que, junto a ejemplos como la concha de vieira de Santiago de Compostela, que se cuenta entre las más antiguas insignias conocidas en occidente, se van incorporando ya motivos más simplificados, alusivos y, por tanto, de carácter más «emble-

9. En Hch 19,24-26, leemos: "Cierto platero, llamado Demetrio, que labraba en plata templetes de Artemisa y proporcionaba no pocas ganancias a los artífices, reunió a éstos y también a los obreros de este ramo, y les dijo: 'Compañeros, vosotros sabéis que a esta industria debemos el bienestar; pero estáis viendo y oyendo decir que no solamente en Éfeso, sino en casi toda el Asia, ese Pablo persuade y aparta a mucha gente, diciendo que no son dioses los que se fabrican con las manos'». En la Antigüedad, estas insignias-testimonio de la visita a un santuario eran privilegio reservado inicialmente a peregrinos de alto rango, o bien dignatarios y mandatarios principescos. 10. La fabricación y comercio de esta clase de insignias, elaboradas por cofradías de artesanos que trabajaban en grandes talleres instalados cerca de los santuarios, y que proporcionaban una renta nada despreciable, se llevaba a cabo bajo el control riguroso de la Iglesia, que trató por todos los medios de mantener su monopolio en dura competencia con los mercaderes particulares. Su producción se incrementaba exponencialmente a raíz de acontecimientos milagrosos, con ocasión de ciertas celebraciones religiosas, o gracias a la hábil promoción de algún complejo devocional (vid. Bruna, 2007: 44). Tal proliferación de recuerdos, que condujo a su banalización y convirtió al peregrino de fines de la Edad Media en una especie de coleccionista de souvenirs, llevó a Erasmo de Rotterdam a afirmar que «estos tiempos están cubiertos de insignias» hasta el punto de parecer "acorazados». 


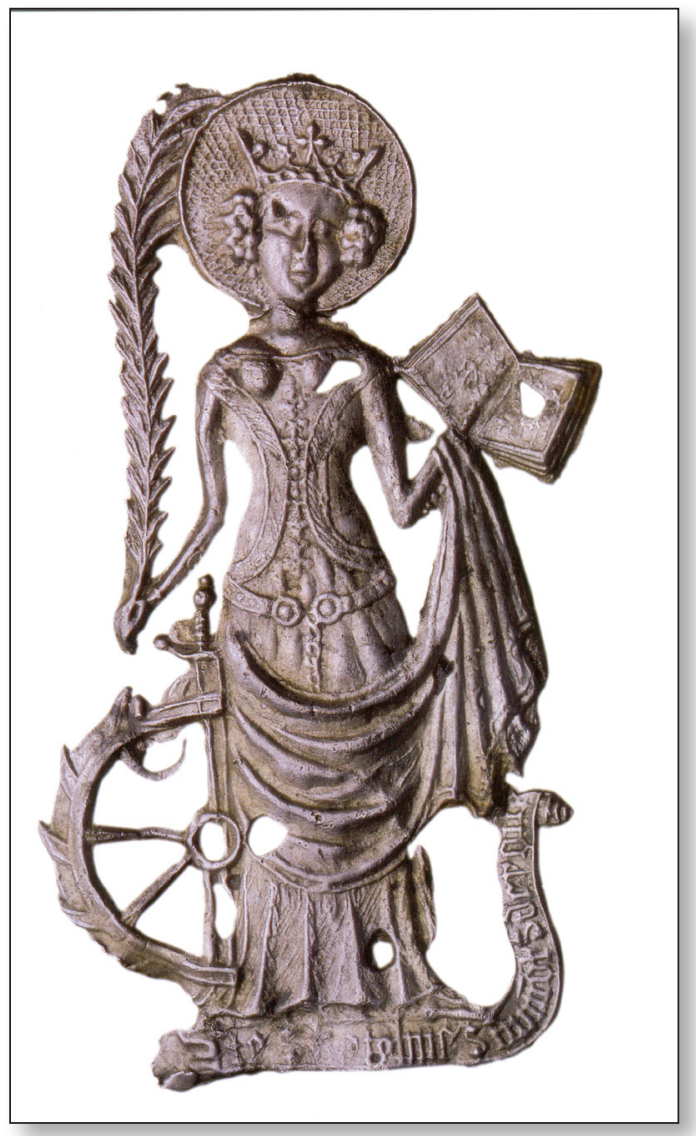

Fig. 1. Santa Catalina, insignia de peregrino con la leyenda "Sainte Kateline du Mont de Rouen", s. XV. Praga, Museo de Artes Decorativas.

mático", como peces, flores o pequeñas espadas como atributo del arcángel san Miguel. ${ }^{11}$ La pintura europea del s. XV, con especial insistencia en la flamenca o la germánica, nos ofrece numerosas evidencias del amplio uso de esta categoría de insignias, bien visibles en las gorras de peregrinos o de mendigos que aguardan en la puerta de los templos la caridad de los devotos. b) Las badges/devises e insignias de librea. Un momento determinante en la evolución de los signa metálicos que aquí nos ocupan se corresponde con los primeros decenios del s. XIV. A partir de las décadas de 1320-40, las armerías tradicionales, fijadas ya definitivamente sobre una rigurosa base normativa, asisten a la disolución de su papel identitario a causa de las particiones o subdivisiones que vienen a complicar su lectura. Este proceso de "parálisis» de la heráldica favoreció en Europa occidental el surgimiento de nuevas formas de carácter emblemático (badges, devises) que servirán de señales particulares de propiedad, y también en ocasiones, a causa de la conflictividad política del momento, de signo de reconocimiento o contraseña para la clientela de los príncipes (Fox-Davies, 1909: 345-359; Hope, 1913: 181-189; Pastoreau, 1981: 129-136; 2003: 218219; 2009: 213-218). ${ }^{12}$ Estas badges personales, figuradas habitualmente con motivos de animales, plantas $u$ objetos diferentes a los que ornan sus escudos familiares, y que se generalizan como elemento identificador de su propietario, ya sea el príncipe emisor de la insignia o un determinado colectivo, parecen constituir, en opinión de Michel Pastoreau (2009: 218), una tentativa por parte de las familias y de los grupos de poder por recuperar un cierto espíritu totémico que las armerías perdieron a causa de su excesiva complicación.

Pronto iniciales, cifras y monogramas de nombres se incorporan al repertorio "proto-emblemático»; a ello se suma la costumbre, ya en la segunda

11. En torno a esta tipología, vid. Bruna, 2007: 20ss; 1999: 622-627; Köster, 1972: 146-160; Mitchiner, 1986; Spencer, 1987-88: 219-224.

12. De especial interés en este sentido son también las reflexiones que Fernando R. de la Flor (1995: 79-107) se plantea a partir del esquema propuesto por Pastoreau.

IMAGO, NÚM. 7, 20I5, 7-23 


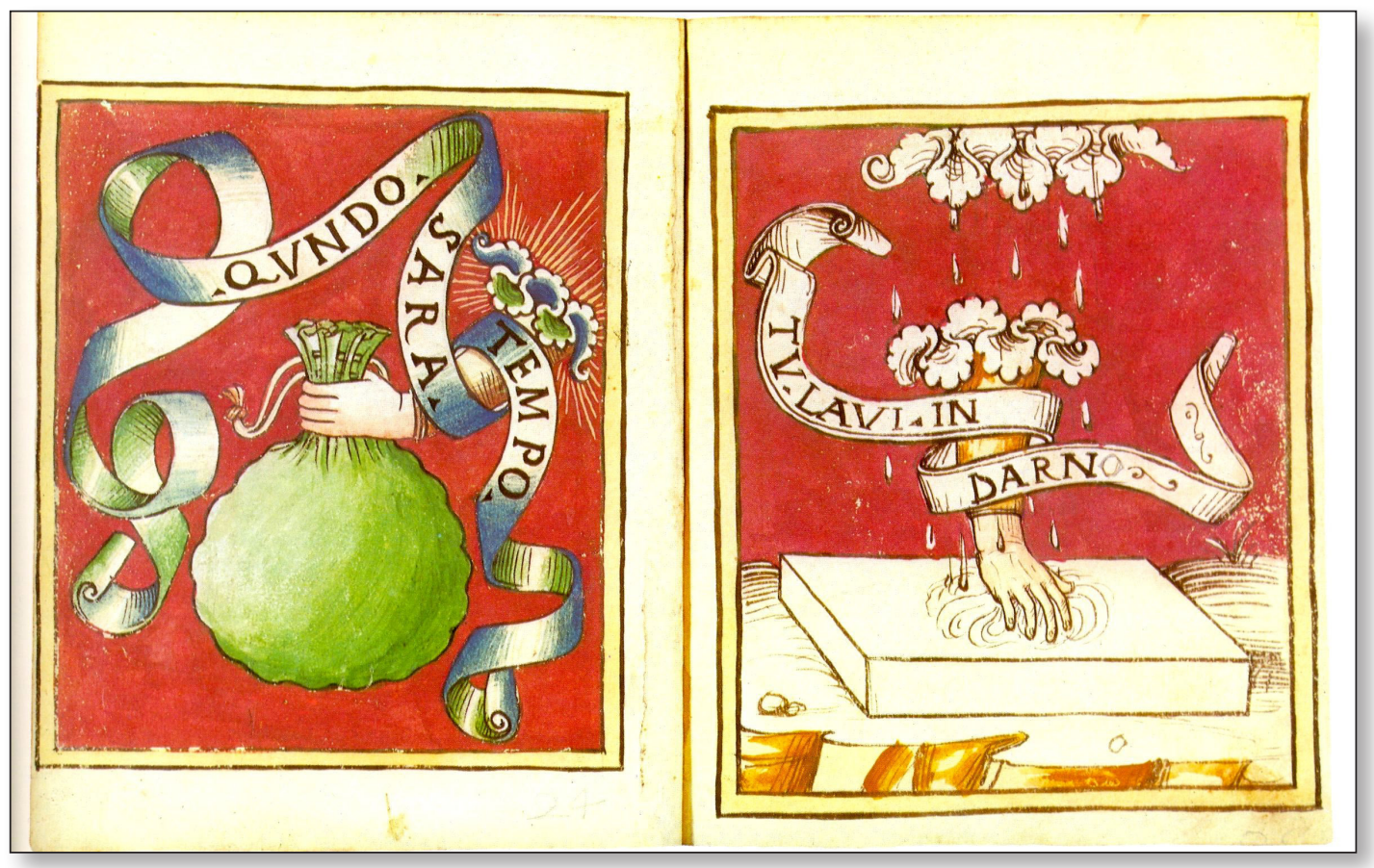

Fig. 2. Divisas de la casa Visconti, recopilación de imprese manuscritas, c. 1490. Milán, Biblioteca Trivulziana, cod. 2168.

mitad del siglo XIV, de acompañar al motivo de una corta sentencia que la completa o explica. Nace así la divisa formada de un «cuerpo» (figura) y un «alma» (lema) que, a diferencia del proverbio, no es ya tanto una máxima de carácter general como una invocación o exhortación de aliento personal, dotada a menudo de un aura enigmática [fig. 2]. La ausencia de reglas precisas que regularan su creación, lo que permite al príncipe dar libre curso a su fantasía, su gusto, su humor o su cultura, explica que el fenómeno del empleo de estas divisas, con o sin mote, resulta- ra ya imparable a fines de la centuria, conociendo su apogeo en las décadas siguientes. Ciertas grandes familias inglesas, francesas e italianas (Lancaster, Borbón, Borgoña, Saboya, Visconti, Sforza...), ya plenamente conscientes del modo en que su ostentación favorecía en el ámbito cortesano la formalización externa de las relaciones sociales y de la actividad política, militar, afectiva, festiva e incluso jurídica, llegaron a hacer un uso inmoderado de las mismas. ${ }^{13}$ Ya sea como motivos decorativos, como signos de identidad, como marcas de propiedad o como indicios de la per-

13. Indica Pastoreau (1981: 131) que un mismo personaje podía poseer, simultánea o sucesivamente, varias badges, y que la misma figura podía servir de «emblema» a diversos portadores. En otro lugar (2009: 213), este mismo autor argumenta que fue precisamente uno de los factores del éxito de las devises el hecho de que, frente a las más restringidas posibilidades expresivas de las armerías, que únicamente traducen la identidad de su portador o su pertenencia a un grupo familiar, las nuevas fórmulas emblemáticas permitían a su poseedor poner de manifiesto a su manera su carácter y temperamento, sus aspiraciones, sus ambiciones o, incluso, sus pulsiones. 
sonalidad de su portador, estos «emblemas» convencionales se convierten a fines de la Edad Media en moda de uso común, no sólo en la sociedad cortesana, fiestas o creación de órdenes de caballería, sino también en la aplicación a la indumentaria del momento, bien en forma de insignias en cinturones, zapatos o joyas, bordados en sombreros y guantes, o grabados sobre las armas personales. ${ }^{14} \mathrm{~A}$ mediados del s. XV son ya elementos esencialmente ornamentales, reducidos a su consumo en costumbres de galantería, afectación o en pasatiempos triviales. ${ }^{15}$ La elaboración de una divisa deviene así un deporte mundano, un entretenimiento intelectual refinado: inventadas de modo habitual por las personas letradas del entorno de los grandes personajes (caso más frecuente), o por el propio príncipe, cada una de ellas exprime algún rasgo notorio de su personalidad: proporcionan así un valioso testimo- nio de las aspiraciones y resignaciones de una élite social en crisis, que busca en el aparato y sus emblemas una deslumbrante compensación al declinar ineluctable de su papel político, económico, militar y social.

En este contexto adquirirán notoria presencia las denominadas insignias "de librea" (Bruna, 2007: 62ss.), esto es, aquellas prendas u objetos investidos con los colores, las armas o las divisas del noble o príncipe que eran distribuidas durante ciertas ceremonias organizadas por éstos, normalmente en las festividades de Navidad, Pascua u otras fechas señaladas. En estos actos, el señor entregaba sus badges a todos los miembros de su casa -familiares, amigos, lacayos, aliados...-, o a sus más fieles caballeros, ${ }^{16}$ bien bordadas en jubones, ligas, fajas, bandoleras o tocas, bien labradas en apliques, joyas, collares o insignias de metal con diseño de broches o colgantes [fig. 3], según

14. Rodríguez de la Flor (1995: 102) reflexiona sobre la indumentaria personal como campo provisto de una alta carga simbólica, y en sus adornos como objetos donde proliferan las connotaciones significantes: «Pero las divisas, los blasones, lo heráldico y decorativo, antes de ser rearticulado todo con otros componentes específicos en el interior de los libros de emblemas renacentistas, pasó también a formar parte de la etiqueta cortesana, integrando los sistemas de signos de prestigio que se expresan en el marco de la corte, en su mundo ritualista, en las fiestas sobre todo, en los juegos, y, también, y muy principalmente, en los vestidos, en el mundo de la moda y en ese universo de objetos de significativa posesión que el sistema capitalista viene a consolidar, como una estrategia de identificación y de integración de las clases altas».

15. De acuerdo con el acertado análisis de Robert Klein (1980: 115-118), durante el tránsito del siglo XV al XVI, las devises pasaron del ámbito militar -las primeras recopilaciones de estas empresas eran "amorosas y militares", también denominadas «heroicas», vinculadas a la caballeresca costumbre extendida en Francia o Italia de ornar armas y estandartes con empresas compuestas de una imagen y una sentencia que los capitanes concedían a sus soldados para reconocerlos y estimular su valor-a los salones cortesanos, donde adquirieron un enorme éxito como improvisado e ingenioso juego de sociedad. Fueron también muy difundidas gracias a la actividad de las academias que, animadas por su afectación filosófica y, con frecuencia, por una elevada dosis de pedantería, empezaron a distinguirse cada una con su propia empresa, obligando también a sus miembros a adoptarlas individualmente. Cf., en este sentido, Praz, 1989: 85, o Margolin, 1981: 67ss., quien analiza con profundidad la relación existente entre las divisas y las armerías medievales, e insiste de igual modo en este proceso de simplificación, vulgarización y despersonalización de la tradición heráldica al desplazarse a todos los ámbitos de la vida civil y social.

16. Paolo Giovio, después de describir al inicio de su Dialogo dell'imprese militare et amorose (1574: 10-11) las empresas y blasones que los antiguos portaban en escudos y yelmos, las que los emperadores romanos hacían acuñar en el reverso de muchas monedas, o las que reyes y caballeros medievales solían ostentar, añade: «Agora en esta edad mas moderna como de Federico Barbaroxa, en cuyo tiempo se introduxo en costumbre las insignias de los linages, que llamamos armas, dados por los Principes, por merecimiento de las sanctas empresas, hechas en la guerra, solo para ennoblecer, y honrar los esforçados Cavalleros, se inventaron diversas invenciones de Cimeros, y pinturas en los escudos»; reproducimos la trad. de Alonso de Ulloa (1562: 4-5).

IMAGO, NÚM. 7, 20I5, 7-23 


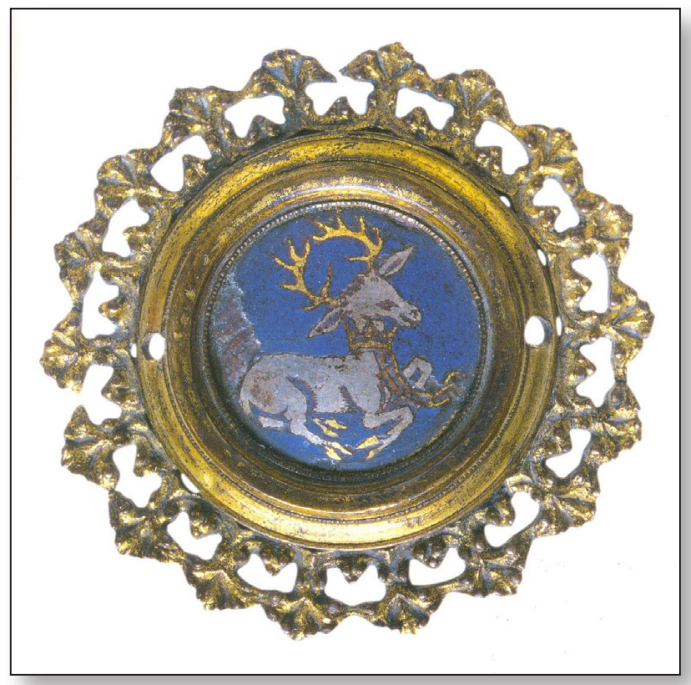

Fig. 3. Broche con la divisa del ciervo blanco de Ricardo II de Inglaterra, fines del s. XIV. Troyes, Museo de Bellas Artes.

su rango y preferencia, de modo que los diversos materiales con que estaban fabricadas -metales comunes o preciosos, a menudo esmaltadospermitían constatar la jerarquía del personal a su servicio. El propósito esencial de estos distintivos de favor era el de insertar en el círculo de sus devotos una suerte de ideal corporativo: además de señal de elegancia y de honrosa distinción, o de prueba de lealtad entre los súbditos fieles, tales badges y broches sirvieron al mismo tiempo, en no pocas ocasiones, como señal de reconocimiento entre los miembros de una misma facción.

c) Insignias de carácter conmemorativo $y$ festivo (Bruna, 2007: 114ss.). Junto a las divisas personales o las insignias de librea, no resulta extraño encontrar asimismo, de modo singular en la Inglaterra de los ss. XIV y XV, signa portátiles conmemorativos de alguna hazaña notable, recordatorios de algún pacto o alianza, o, incluso, indicativos de ciertos derechos o pretensiones territoriales. En el año $1483 \mathrm{el}$

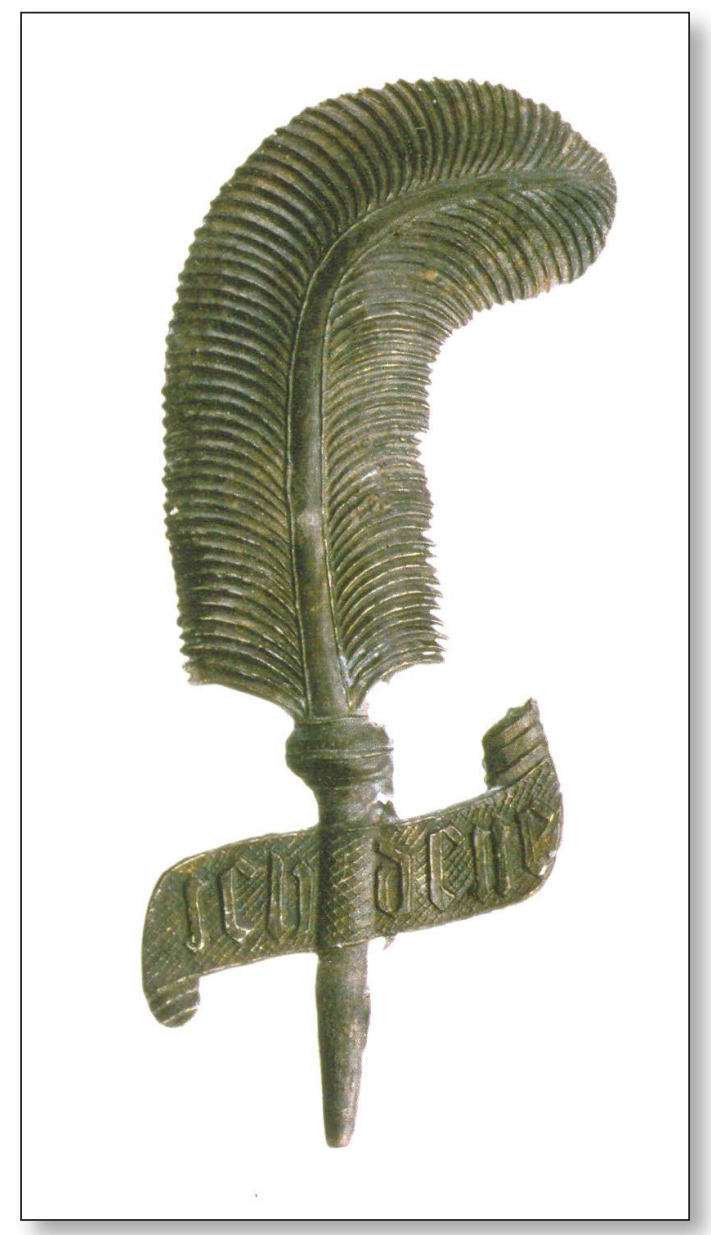

Fig. 4. Pluma de avestruz, badge del Príncipe Negro con el lema "Ich dene (dien)» ( YYo sirvo»), fines del s. XIV. Londres, Museum of London.

rey Ricardo III ordenó la fabricación de 13.000 insignias bordadas sobre tela de pana, figuradas con un jabalí blanco, para su distribución en la precipitada investidura de su hijo Eduardo de Middleham como Príncipe de Gales. También en ciertos casos podían aludir a personajes coetáneos -por lo general hombres ilustres admirados por sus hechos de guerra-, pero emitidas y difundidas después de su muerte para conservar memoria de su valor. Un conocido ejemplo es la pluma de avestruz superpuesta 
a una filacteria con el mote flamenco "Ich dien» ("Yo sirvo») [fig. 4], badge de otro célebre heredero a la corona inglesa, Eduardo de Woodstock (1330-76), más conocido como Príncipe Negro a partir del s. XVI. Broches con este motivo fueron acuñados y difundidos tras las ceremonias póstumas realizadas en su honor, o vendidos a los peregrinos que acudían a su sepulcro en la catedral de Canterbury (Bruna, 2007: 114-17). Aparte de grandes funerales, duelos colectivos y sucesos políticos, ciertas insignias de plomo fueron igualmente fundidas con ocasión de determinados celebraciones o festividades del calendario popular, como la renovación de la naturaleza en el mes de mayo. Con todas estas variantes se estaba vehiculando al emblema portátil hacia una nueva función testimonial: la de «objeto-memoria» de un determinado suceso o acontecimiento.

d) Insignias de asunto amoroso (Bruna, 2007: 73ss). También en torno al 1300 surge otra significativa variante temática de este tipo de apliques, acorde en este caso con una corriente de refinamiento y elegancia que se extiende a las costumbres y bienes de lujo al alcance de príncipes y grandes burgueses. Muchos de los productos procedentes de los talleres eborarios y de orfebres aparecen ornados con motivos galantes, o se inspiran en las novelas coetáneas de caballería. Se reiteran de este modo convencionales escenas del amor cortés, ideal caballeresco cantado a través de los versos de los trovadores en las cortes señoriales, de acuerdo con poemas como el Roman de la Rose: la coronación de la amada con una guirnalda vegetal, la declaración de su amor por parte del pretendiente, como sumiso vasallo arrodillado a los pies de su dama-reina, la pareja que intercambia una flor, o la composición de los dos amantes instalados sobre las ramas de un árbol, donde ella tiende una corona de flores y hojas al hombre, en tanto éste confía el corazón a su compañera... Se trata en todos los casos de escenas de aire cortesano, con personajes ricamente vestidos emplazados en jardines, y cuyos gestos esenciales simbolizan de forma estereotipada el ritual amoroso. Paralelamente a estos pasajes, numerosos motivos-tópicos de la lírica cortés serán igualmente individualizados y acuñados en metal, en varios casos con su breve sentencia referida a los conceptos de la belleza y el deseo: rosas y otras flores, tórtolas, cisnes [fig. 5], halcones y una interminable serie de corazones, a menudo coronados o traspasados de una flecha o filacteria que porta el lema "Amour».

e) Insignias de temática fantástica o demoníaca (Bruna, 2007: 139ss.). El catálogo de signa portátiles medievales finaliza con un grupo más marginal de figuras de hombres y mujeres salvajes, de criaturas híbridas como sirenas,

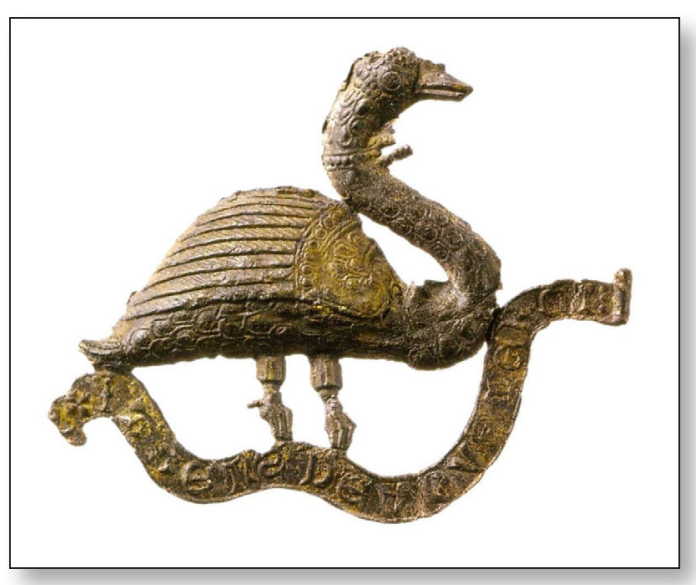

Fig. 5. Cisne, insignia con el lema "Jatens de vous merci" ("Espero de vos el alivio»), $2^{a}$ mitad del s. XV. París, Museo Nacional de la Edad Media de Cluny. 
diablos tricéfalos o brujas, escenas burlescas o de un sorprendente imaginario abiertamente sexual. Estas criaturas monstruosas, violentas o ambivalentes actuaron de forma indudable como talismanes, como eficaces fetiches destinados a repeler y conjurar amenazas maléficas invisibles, o determinadas maldiciones o invocaciones, de acuerdo con el viejo principio de combatir el mal por medio del mal.

\section{LAS ENSEIGNES CORTESANAS DEL QUINIENTOS}

Como ya se ha indicado, desde los decenios centrales del s. XIV vemos proliferar en la indumentaria de nobles y cortesanos un nuevo tipo de broche que rivaliza con las figuras de santos y reliquias que portan los peregrinos: se trata ya de auténticas badges o devises, nacidas de la nueva sociedad curial, de la etiqueta, de las fiestas (torneos, justas, paradas, mascaradas...), o de la creación y multiplicación de las órdenes de caballería, que son ostentadas como signos de identidad, de posición social o como indicios de la personalidad. Acompañadas o no de las armerías familiares, favorecidas por el ya indicado auge de una atracción por los bienes suntuarios, las divisas menudean sobre todo tipo de accesorios de la vestimenta, así como en numerosas obras de arte y monumentos, a los que aportan una dimensión secular. De este modo la enseigne, significativo producto a medio camino entre el giro intelectual que aproxima la divisa medieval al género de la Emblemática literaria y un renaciente culto a la personalidad, ya plenamente concebida como marca de identidad y distinción, se convierte en el adorno masculino más característico de príncipes, nobles y gentilhombres a lo largo del s. XVI (Hackenbroch, 1996: "Introduction»). ${ }^{17}$ Como elemento que revela aspectos de la personalidad de quien los porta -carácter, intereses, aspiraciones, inclinaciones culturales, gustos artísticos...-, estas insignias ya se fabrican de modo individual, a base de materiales preciosos y refinadas técnicas ornamentales de orfebrería y esmaltes. Como sucedió con sus precedentes medievales, sólo unas pocas piezas originales han sobrevivido, en comparación con las muchas conocidas a partir de los retratos de sus propietarios originales, o de los repertorios de diseños que nos dejaron Etienne Delaune, Hans Holbein el Joven, Hans Sebald Beham o Erasmus Hornick, ilustrativo testimonio de su éxito y difusión.

Igual que ya hiciera Paolo Giovio al concretar las circunstancias históricas que promovieron la renovación de las imprese modernas, ${ }^{18}$ Hackenbroch (1996: "Introduction») establece como momento decisivo en la evolución de estas insignias en el Renacimiento temprano la invasión de Italia por parte de Carlos VIII de Francia en 1494-95. Como resulta bien conocido, los miembros de su ejército portaron vistosos distintivos militares sobre los sayones o capas, llamativa moda de raigambre medieval que fue actualizada por medallistas, orfe-

17. El empleo de estos broches superó el círculo de los aristócratas, siendo también emulado por ciertos intelectuales y comerciantes carentes de heráldica propia. En ocasiones, eran adoptados como elemento constitutivo de un disfraz para algún tipo de celebración o evento, como las justas de disfraces características de la Inglaterra isabelina.

18. «Pero en nuestros tiempos despues de la venida en Italia del rey Carlos Octavo, y de Ludovico XI, todos los que seguian la militia, imitando a los Capitanes Franceses, procuraron de se adornar, de gentiles, y pomposas empresas, de las quales reluzian los Cavalleros appartada cada compañía por si con diversas libreas; porque bordaban de plata, y oro de martillo, los sayones y sobrevestas, y en los pechos, y spaldas estaban las empresas de los capitanes: de manera, que las muestras de las gentes d'armas hazian pomposissimo, y riquissimo espectáculo, y en la batalla se conoscia el esfuerço, y bondad de las compañías» (Giovio, 1574: 11); trad. cit. de Alonso de Ulloa (1562: 5). 
bres y joyeros, quienes canalizan esta costumbre de las divisas bordadas y portátiles, pero adaptando su temática a los nuevos tiempos: en convivencia con los tradicionales asuntos religiosos, heroicos o amorosos, que continúan manteniendo su vigencia, los temas humanistas aparecen como emergente alternativa. Este nuevo imaginario fue nutrido desde la traducción y glosa de los antiguos textos clásicos, ya disponibles en ediciones impresas, que expanden el conocimiento de la mitología griega y la historia romana, a menudo sometidas a oscuras interpretaciones procedentes de las academias neoplatónicas, empeñadas en reconciliar puntos de vista cristianos y paganos. El lenguaje de las enseignes se convierte así en el mismo de las imprese literarias: una suerte de código enigmático, no siempre fácil de descifrar, hecho de diseños, cifras o adivinanzas, a través de los cuales se puede deducir el intento de su portador. También jugarán un importante papel en este proceso las monedas y camafeos romanos procedentes de excavaciones, que suponían incentivos adicionales para aproximar las insignias de ropajes y gorras al repertorio clásico. Testimonio de esta especie de pulso entre los asuntos gentiles y los bíblicos fueron las respectivas opciones de Francisco I de Francia y Maximiliano I de Habsburgo: frente al Hércules gálico -Hercule Gaulois-, fundador mítico de París, adoptado por el monarca francés a partir de 1510-15 como modelo de virtud, fuerza y elocuencia (Hackenbroch, 1996: 40-44), ${ }^{19}$ tal y como pusiera de manifiesto Andrea Alciato en sus Emblemata, ${ }^{20}$ el dirigente del Sacro Imperio optó para el ornato de sus gorras por la efigie de la Virgen apocalíptica [fig. 6], protectora de sus amplias posesiones, que diversos sucesores mantuvieron en sus sombreros (Hackenbroch, 1996: 202ss.).

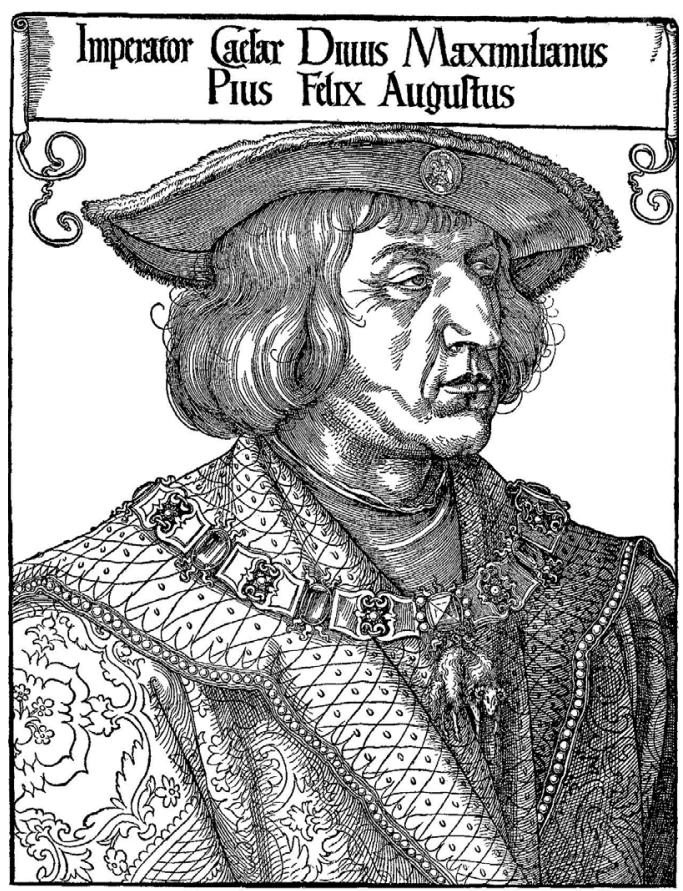

Fig. 6. Alberto Durero, Retrato del emperador Maximiliano I, grabado xilográfico, c. 1519.

Podemos afirmar, tras hacer un rápido repaso de los escasos ejemplares conservados, o a partir de su identificación en la retratística del momento, que, como consecuencia de aquella confluencia de tendencias, la temática de las insignias figuradas del quinientos fue de lo más diversa. Prácticamente se detecta un equilibrio entre los asuntos religiosos o devocionales y los de inspiración pagana. Entre los primeros merecen reseñarse composiciones perfectamente reconocibles de la vida de la Virgen María y de los libros del Antiguo Testamento -la Pasión de Cristo, sin embargo, apenas se encuentra presente en este ámbito-, junto a imágenes de una larga serie de santos patrones y protectores, entre los que cabría destacar por su reiteración san Jorge, san Juan

19. Véase, como ejemplo, el retrato anónimo de Francisco I (Escuela francesa, Londres, Society of Antiquaries, Kerrich Becquest, 1510-15).

20. Eloqventia fortitudine praestantior, emblema 180 de la ed. de Santiago Sebastián (1985: 223).

IMAGO, NÚM. 7, 20I5, 7-23 


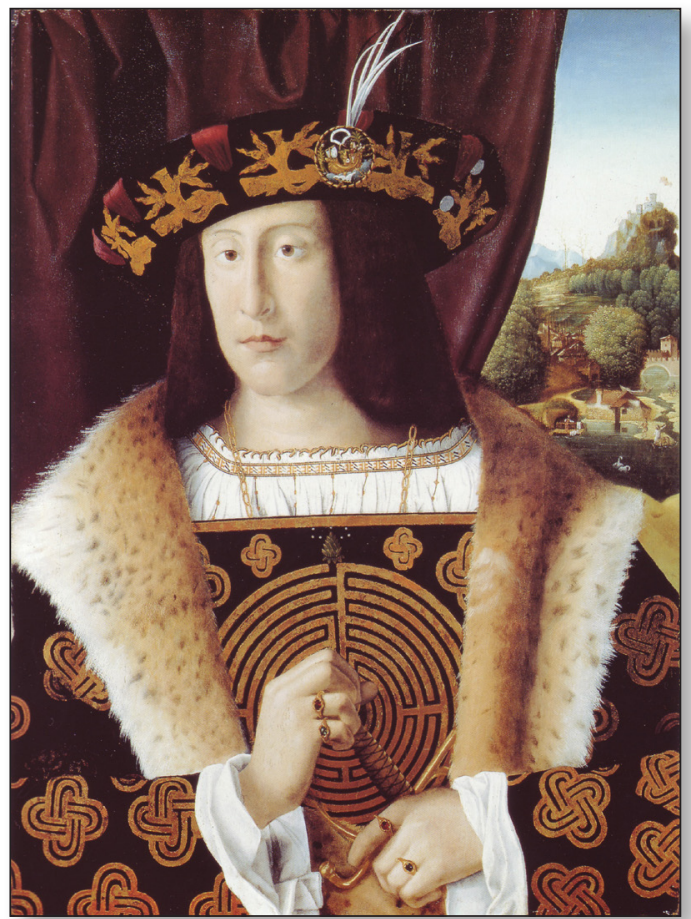

Fig. 7. Bartolomeo Veneto, Retrato de un caballero, c. 1500-22. Cambridge, Fitzwilliam Museum.

Bautista, santa Bárbara o san Cristóbal. A ello deben sumarse las numerosas personificaciones de virtudes cristianas, encabezadas por la Prudencia portando un espejo y una serpiente, ${ }^{21}$ o el Miles christianus combatiendo desde su corcel a los enemigos de la fe. Por su parte, otros nobles caballeros más en sintonía con las nuevas corrientes ideológicas, escogieron sus figuras de entre los diversos temas ofrecidos por la literatura y la historia clásicas, o a partir del repertorio de dioses y héroes míticos, desde Marte a Hércules, incluyendo frecuentes asuntos eróticos, protagonizados unas veces por Venus, Amor o las ninfas, otras por personajes anónimos, o ejemplificados en el tópico del

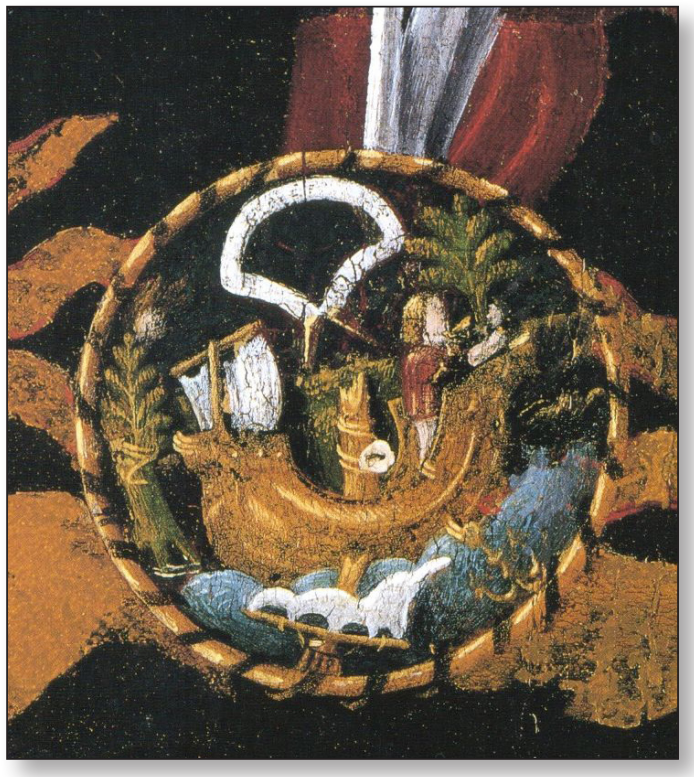

Fig. 8. Bartolomeo Veneto, Retrato de un caballero, c. 1500-22. Cambridge, Fitzwilliam Museum. Detalle del medallón del sombrero.

Juicio de Paris. Muy pocas de ellas portan algún tipo de lema inteligible -normalmente inscripciones identificativas o alusivas en el caso de los santos y escenas bíblicas-, y son verdaderamente escasas las insignias de sombrero que nos han llegado concebidas como verdaderas divisas, con su doble componente gráfico-textual y la adecuada dosis de hermetismo. Estas últimas, salvo excepciones, se ubican fundamentalmente en el contexto de las cortes italianas. Al hilo de este argumento resultan muy ilustrativas sendas obras del pintor Bartolomeo Veneto: una de ellas es el Retrato de un caballero, posible miembro de la familia Gonzaga, del Fitzwilliam Museum de Cambridge (150022), ampliamente conocido por el vistoso laberinto y los nudos gordianos que ornan su tabardo [fig. 7]; en el broche circular del

21. En opinión de Yvonne Hackenbroch (1996: 375), fueron las directrices reformadas de Lutero, Calvino y Zwinglio en relación a su propuesta de una vía directa de comunicación con Dios, anulando así la intercesión de la Virgen y los Santos, las que propiciaron la abundancia de personificaciones de Virtudes en las enseignes, presididas por la omnipresente Prudencia, especialmente enaltecida por pensadores como Maquiavelo y Budé. Además de las cristianas, no resulta extraño encontrar otro tipo de alegorizaciones como la Fortuna o la Fama. 


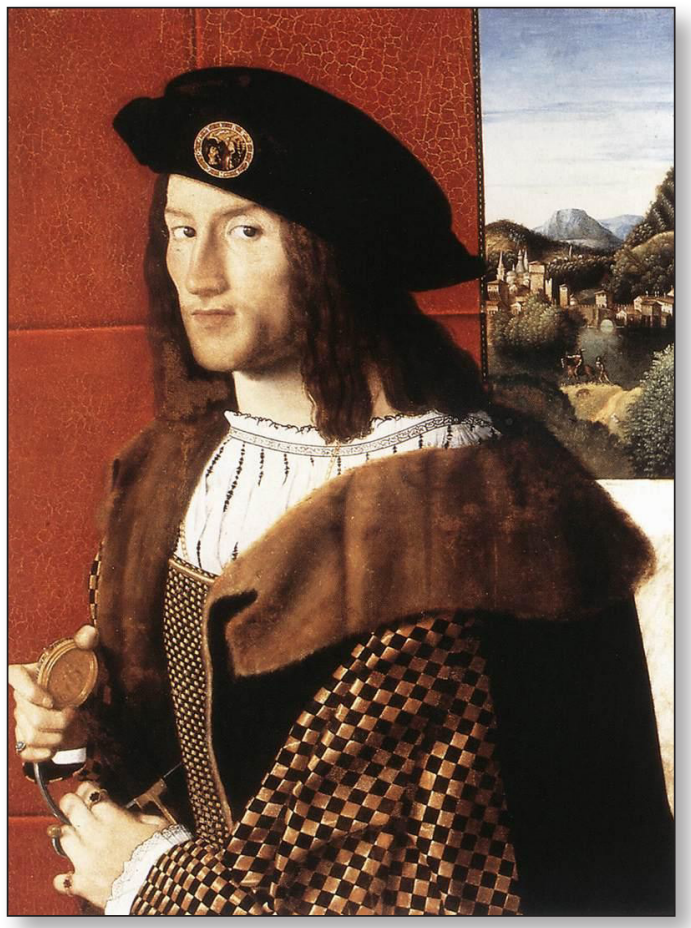

Fig. 9. Bartolomeo Veneto, Retrato de un caballero, c. 1520. Roma, Galleria Nazionale d'Arte Antica, Palazzo Barberini.

sombrero [fig. 8] distinguimos una enigmática escena en la que un navegante, a bordo de un navío con el mástil partido en medio de un mar embravecido, se torna hacia otra figura que sujeta un árbol verde - ¿signo de la esperanza que augura la proximidad de la costa?-, con la letra "Esperance me guide» sobre una banderola al viento. En otro Retrato de un joven noble (Galleria Nazionale, Palacio Barberini, Roma, c. 1520) [fig. 9], el llamativo medallón de la gorra del retrata- do muestra a una dama sujetando una vara dorada, junto a un rosal, enfrentada a un león sedente -otro león huye en la lejanía-, con el mote "Probasti et cognovisti» [Tú me escrutas y conoces] (Sal 139, 1), oscura escena en apariencia alusiva a los sacrificios a que se someten los amantes. ${ }^{22} \mathrm{~A}$ veces las figuras de las enseignes pueden ponerse en relación con fuentes impresas fácilmente identificables, aunque estas últimas sean muy posteriores al cuadro pintado: en el retrato de Hipólito de Médicis con vestido húngaro realizado por Tiziano (Galería Palatina de Florencia, 1535), se incorpora al sombrero la empresa del cometa con el lema «Inter omnes», posteriormente recogida por Paolo Giovio (1574: 53-54); en la efigie de otro Joven noble de Bartolomeo Veneto, conservada en el Museum of Fine Arts de Houston, Texas (c. 1520-23), su protagonista porta ostensiblemente en la boina un toro blanco alado, sin mote, similar al motivo de la empresa de Renato, rey de Sicilia, que recogerá Gabrielle Simeoni en su repertorio de imprese, compuesta de un buey con la banda con sus armas al cuello y la letra "Pas a pas», ${ }^{23}$ en el Joven caballero de Jan Mostaert conservado en la Colección Kisters, Kreuzlingen (c. 1529), en fin, la gran insignia circular de su amplio sombrero encierra un girasol, motivo que, de acuerdo con Claude Paradin, ${ }^{24}$ puede significar al devoto cuyos actos, pensamientos y voluntad están orientados hacia la luz de Justicia de Dios.

El éxito de las enseignes de sombreros resultó muy desigual en los distintos estados europeos del momento, con un grado de

22. Pocos ejemplos más podrían citarse en esta línea. En el retrato doble de Girolamo Romanino titulado Amantes abrazados (Museo de Bellas Artes, Budapest, c. 1520), el medallón del personaje masculino muestra a un ave, con la letra griega $A E T O V$, referida por tanto al águila, si bien la figura recuerda más bien a una paloma. En otro retrato anónimo, esta vez de Jan Gossaert (Un noble, personaje posiblemente de origen portugués, conservado en el Sterling and Francine Clark Art Institute, Williamstown, Massachusetts, c. 1520-30), puede distinguirse en el broche del sombrero a un caballero - ¿el mismo retratado?- abrazando una torre, con la larga sentencia "A qui par trop embrace en vain son bras las", equivalente al proverbio español "Quien mucho abarca, poco aprieta». Otras enseignes de retratos de las primeras décadas del s. XVI muestran inscripciones, indescifrables o ilegibles, o filacterias carentes de texto a causa de su reducido tamaño.

23. Le imprese heroiche et morali ritrovate da M. Gabriello Symeoni Fiorentino (1574: 195).

24. Vid. la divisa de Margarita, reina de Navarra, incluida en sus Devises herö̈ques (1557: 41-42).

IMAGO, NÚM. 7, 20I5, 7-23 
implantación siempre dependiente de las peculiaridades culturales e ideológicas en cada caso. Con la llegada al trono de Francia de Francisco I en 1515, el monarca se afanó en reunir como motivos ornamentales aquellos temas de la Antigüedad en los cuales había sido adecuadamente iniciado por su mentor humanista, Guillaume Budé; sin embargo, pese a ello, la prolongada e intensa tradición impuesta por las insignias de peregrinos explica que otros monarcas y príncipes galos optaran por motivos más devocionales, y prefirieran mostrar en público las efigies oficiales de sus santos patrones, como san Denis o san Miguel. Por contra, en Italia, donde el modelo francés de enseigne llegó a convertirse en el más difundido ornamento de la nobleza (Hackenbroch, 1996: 91), y donde la temprana irrupción de la medalla renacentista desde el segundo cuarto del s. XV supuso un importante estímulo como nueva forma de arte gracias a las innovaciones de Pisanello, la moda de la medaglia di beretto o di capello se propagó de manera fulgurante. Es aquí donde este tipo de distintivos celebran de manera más explícita las elevadas cualidades de mente y espíritu de sus portadores. Los eruditos humanistas de los círculos académicos o cortesanos sugerían los temas y motes más apropiados, inspirados muchas veces en la exégesis neoplatónica, en los repertorios de emblemas y empresas, o en los bronces, camafeos, monedas o intaglios antiguos procedentes de las excavaciones. En este contexto, menudean en las insignias los asuntos procedentes de la mitología e historia antigua, o, como hemos comprobado más arriba, las auténticas imprese con su correspondiente lema en combinaciones más o menos enigmáticas, pudiendo equipararse cuantitativamente a las figuras de la
Virgen, el santoral o los pasajes escrituarios. Los nobles y elegantes caballeros gustaban de mostrar emblemas o divisas accesibles únicamente a un selecto grupo de amigos iniciados, en sutiles juegos de ingenio y erudición que se intensificaron con la corriente manierista.

También los Habsburgo adoptaron de manera bastante generalizada la moda de las insignias portátiles, especialmente después del matrimonio de Maximiliano I con Blanca María Sforza en 1494. Seguramente su posición en los conflictos de religión vividos en el umbral de los tiempos modernos impelió al emperador del Sacro Imperio Romano y a los miembros principales de su corte a elegir casi con exclusividad asuntos devotos, con preferencia por la Virgen María con el Niño, además de otros santos, o bustos de notables emperadores romanos o medievales, resultando casi anecdótica la presencia de personificaciones paganas. ${ }^{25}$ Cuando España llegó a ser parte del imperio de los Austrias bajo Maximiliano, el uso de las insignias figuradas se limitó tan sólo a los círculos más próximos a la corte, rechazo tal vez debido, al menos en parte, al resentimiento de la nobleza española ante las imposiciones de las directrices imperiales (Hackenbroch, 1996: «Introduction»).

Algo similar parece haber sucedido en los estados alemanes, donde las poderosas familias patricias y comerciantes de las prósperas ciudades libres -Freie Reichsstädte- gozaron de una cierta independencia que les permitió establecer sus propios protocolos ceremoniales -o bien su total ausencia- en una muestra de orgullo cívico que condujo a un rechazo más o menos sutil de la moda cortesana, incluyendo, aparentemente, las insignias de los sombreros. Por lo que sabemos, ningún miembro de las principales

25. Significativo es el caso de algunos retratos juveniles del futuro emperador Carlos V; aparte de broches con la figura protectora de san Andrés, o con la vieja divisa borgoñona del pedernal y el eslabón restallando centellas procedente del collar del Toisón de oro, en el conocido retrato colectivo de Bernhard Strigel titulado La familia del emperador Maximiliano (Viena, Kunsthistorisches Museum, c. 1515), resulta reconocible en la gorra negra de Carlos la personificación clásica de la Fortuna. 


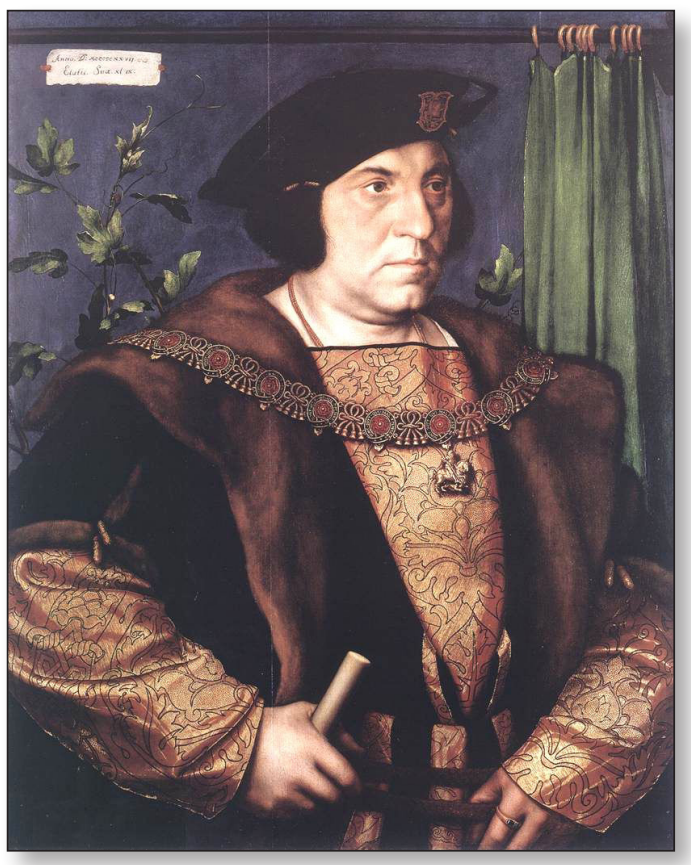

Fig. 10. Hans Holbein el Joven, Retrato de sir Henry Guildford, 1527. Windsor, Colecciones Reales.

familias de banqueros como los Fugger o Welser llegaron a portar broches figurados en sus gorras; sólo los electores palatinos, y otros personajes próximos a la Corte, parecen haberse afiliado a esta costumbre (Hackenbroch, 1996: 282-283).

Por último, en el caso de los Tudor ingleses, Enrique VIII raramente portó insignias, al menos en sus retratos oficiales, posiblemente a causa de las convicciones políticoreligiosas de sus últimos años, cuando se erigió en cabeza de la nueva Iglesia anglicana, o tal vez reacio a ostentar el mismo tipo de distintivos que adornaban a los gobernantes católicos del continente. Resulta difícil saber si de joven lució tales brooches for bonnets. La fugaz historia de las «insignias Tudor» se debe fundamentalmente a la presencia de Hans Holbein el Joven en Londres; en cualquier caso, siguiendo el ejemplo del monarca, los miembros de la casa real apenas las lucieron, y, cuando lo hacían, se trataba de un tipo de badges denominadas «shields and targets", indicativas de sus oficios [fig. 10] o de sus conexiones familiares, lejos de cualquier tipo de interferencia en los asuntos dinásticos. Como alternativa, los bonetes de la familia Tudor mostraron su magnificencia con un generoso despliegue de piedras preciosas, perlas o camafeos, en este último caso como tímida muestra de sus inclinaciones intelectuales (Hackenbroch, 1996: 324-325); en contraste con los varones, y de forma paradójica, solamente las damas de la corte hicieron pleno uso de diseños figurativos en su joyería personal.

La moda de las insignias figuradas en los sombreros no sobrevivió al s. XVI. Según unos, fueron los cambios religiosos, políti$\cos$ y sociales resultantes de la Contrarreforma y el Manierismo los que llevaron a su fin esta práctica: los dictados del Concilio de Trento (1545-63), la Inquisición y la intolerancia religiosa parecen haber extendido una cierta desconfianza hacia las invenciones humanistas, al tiempo que un manifiesto desánimo a la hora de manifestar los sueños, ambiciones y convicciones personales, recelo que se sumó a un creciente rigor y austeridad en la moda de vestir cortesana. Se buscaba, en consecuencia, un tipo de ornato totalmente desprovisto de connotaciones ideológicas sospechosas. En este sentido, las piedras preciosas y gemas procedentes de ultramar, con un tamaño e intensidad de color desconocidos hasta entonces, o los penachos de plumas dispuestos en los rígidos y altos sombreros negros, ofrecían una alternativa puramente ornamental, y fueron mostrados con exuberancia barroca en joyas diseñadas a partir de repertorios impresos. Para otros, por su parte, fueron los excesos de la galantería, la afectación, el abuso de los juegos de palabras, el oscurantismo de las significaciones o la atribución de las divisas a personajes imaginarios lo que condujo a su creciente 
falta de vitalidad, hasta llegar al agotamiento. Sea como fuere, con el devenir de las nuevas realidades que se anunciaban con la llegada del seiscientos desapareció una de las creaciones que, lejos de su aparente frivolidad, supo reflejar de manera más íntima que el resto la dimensión social y mental del trascendental proceso de transformación que determinó el nacimiento de la Edad Moderna.

\section{BIBLIOGRAFÍA}

Alciato, A. [1531]. Viri clarissimi D. Andreae Alciati Iurisconsultiss. Mediola. ad D. Chonradum Peutingerum Augustanum, Iurisconsultum Emblematum liber, Augsburgo, Henry Steyner.

Balavoine, C. [1982]. «Les Emblemes d'Alciat: Sens et contresens", en L'Emblème a la Renaissance, Paris, Société Française des Seiziémistes, 49-59.

BrunA, D. [1996]. Les Enseignes de pèlerinage et les enseignes profanes au musée national du Moyen Âge (catálogo de la colección), Paris, Réunion des Musées Nationaux.

— [1999]. "Les enseignes de pèlerinage», en C. Prigent (Dir.), Art et societé en France au $X V^{e}$ siècle, París, Maisonneuve et Larose, 622-627.

- [2006]. Enseignes de plomb et autres menus chosettes du Moyen Âge, Paris, Le Léopard d'Or.

- [2007]. Saints et diables au chapeau. Bijoux oubliés du Moyen Âge, Paris, Éditions du Seuil.

Covarrubias Orozco, S. [1611]. Tesoro de la lengua castellana o española, Madrid, Luis Sánchez (citamos por la edición de Madrid, Turner, 1984).

Fox-Davies, A. C. [1909], A Complete Guide to Heraldry, Londres, T. C. and E. C. Jack (reeditado en edición revisada y anotada de J. P. Brooke-Little, Londres, Nelson, 1969).
Giovio, P. [1574]. Dialogo dell'imprese militare et amorose, Lyon, Guillaume Roville.

Hackenbroch, Y. [1996]. Enseignes: Renaissance Hat Jewels, Firenze, Studio per Edizioni Scelte (S.P.E.S.).

Hope, J. [1913]. Heraldry for Craftsmen and Designers, Londres.

Horozco y Covarrubias, J. de [1604]. Emblemas morales, Çaragoça, Alonso Rodríguez.

KLein, R. [1980]. «La teoría de la expresión figurada en los tratados italianos sobre las 'imprese', 1555-1562», en La forma y lo inteligible. Escritos sobre el Renacimiento y el arte moderno, Madrid, Taurus, 115-137.

Köster, K. [1972]. "Insignes de pèlerins et objets de devotion", en Rhin-Meuse, art et civilisation, 800-1400 (catálogo de exposición), Colonia/Bruselas, 146-160.

Maravall, J. A. [1984]. "La literatura de emblemas como técnica de acción sociocultural en el Barroco", en Estudios de historia del pensamiento español, serie tercera: El siglo del Barroco, Madrid, Ediciones de Cultura Hispánica, 197-222.

Margolin, J.-C. [1981]. «Devises: armes parlantes et rebús au temps des grands rhetoriqueurs», en Emblemes et devises au temps de la Renaissance, París, Jean Touzot, 65-80.

Miedema, H. [1968]. "The Term 'Emblema' in Alciati", Journal of the Warburg and Courtauld Institutes, 31, 234-250.

Mitchiner, M. [1986]. Medieval Pilgrim and Secular Badges, Londres, Hawkins Publ.

Pastoreau, M. [1981]. "Aux origines de l'Embleme: La crise de l'Heraldique européenne aux $\mathrm{XV}^{\mathrm{e}}$ et $\mathrm{XVI}^{\mathrm{e}}$ siecles», en Emblemes et devises au temps de la Renaissance, París, Jean Touzot, 129-136.

- [2003]. Traité d'héraldique, París, Picard Éditeur.

- [2009]. L'art héraldique au Moyen Âge, París, Éditions du Seuil. 
Praz, M. [1989]. "La filosofía del cortesano», en Imágenes del Barroco (Estudios de emblemática), Madrid, Siruela, 67-97.

RodríGUez de LA Flor, F. [1995]. "Los contornos del emblema: del escudo heráldico a la divisa y la empresa», en Emblemas. Lecturas de la imagen simbólica, Madrid, Alianza Forma, 79-107.

Sebastián López, S. [1985]. Alciato: Emblemas, Madrid, Akal, 1985.

SimeOnI, G. [1574]. Le imprese heroiche et morali ritrovate da M. Gabriello Symeoni Fiorentino. Lyon, Guillaume Roville (la obra se añade a la citada de Paolo Giovio, continuando su numeración).
Spencer, B. [1987-88]. "Pilgrim Souvenirs", en Age of Chivalry, Art in Plantagenet England 1200-1400 (catálogo de exposición), Londres, 219-224.

UlloA, A. De [1562]. Dialogo de las empresas militares, y amorosas, compuesto en lengua italiana, por el illustre, y reverendissimo Señor Paulo Iovio Obispo de Nucera, Lyon, Guillaume Roville, 1562. 
